\title{
Museu, poder e disciplina: análises sobre sua relação com os públicos escolares
}

Museum, power and discipline: analysis about its relationship with its students audience

Renata da Silva Montechiare Pires*

\section{Resumo}

Este trabalho é parte da pesquisa sobre museus etnográficos e seus patrimônios criados na segunda metade do século XIX na Europa, ainda em atividade hoje. Tem-se o objetivo de refletir sobre as contribuições de Michel Foucault para o estudo dos museus e sua relação com a escola, no que diz respeito ao espaço, à arquitetura e à prática social. À luz da etnografia realizada em um museu de antropologia, este estudo se propõe a debater sistemas disciplinares. Para tanto, é o minucioso trabalho de preparação do museu para a recepção de grupos de crianças das escolas que desperta o interesse para as análises que se seguem.

Palavras-chave: Escola. Michel Foucault. Museu. Sistema disciplinar.

\section{Abstract}

This work is part of a project about $19^{\text {th }}$ century ethnographic museum in Europe. The focus here examines how Michel Foucault contributes to reflections about museum studies, especially considering schools, space, architecture and social practice. Based on the ethnography done in an anthropological museum, this paper aims to discuss the disciplinary system argued by Foucault in Discipline and Punish (1975). To conclude this purpose, the analysis comes from how museum workers interact in the reception of groups of local schools and children.

Keywords: Disciplinary system. Michel Foucault. Museum. School.

Recebido em: 07/01/2017 - Aprovado em: 11/07/2017

http://dx.doi.org/10.5335/rep.v24i3.7767

Doutora pelo Programa de Pós-Graduação em Sociologia e Antropologia da Universidade Federal do Rio de Janeiro (2017). Editora da Revista Enfoques e pesquisadora do Laares (http://www.laares-ufrj.com/). E-mail: rmontechiare@ gmail.com 


\section{Introdução}

Entrada do Museo Nacional de Antropología de Madrid, 10h da manhã, terça-feira. Um grupo de 30 crianças com cerca de 8 anos de idade chega ao museu acompanhado de duas professoras. Descem do ônibus e são rapidamente organizadas em fila na calçada em frente ao museu. $\mathrm{O}$ grupo caminha em direção ao portão de entrada, área limítrofe que separa o espaço da rua do espaço do museu. Nesta pequena área aberta, aos pés das escadas que levam à monumental entrada do museu, com suas quatro enormes colunas jônicas, as 30 crianças são reorganizadas em dois grupos de 15. Cada uma delas recebe um pequeno sinal de tinta no nariz: um grupo terá todas as crianças com narizes marcados de branco, e o outro grupo marcado de amarelo. Uniformizadas, as crianças facilmente se destacam entre os demais frequentadores do museu, visitantes e funcionários. São novamente postas em fila: cada um dos dois grupos de 15 crianças separa meninos e meninas, que compõem filas distintas e organizadas. Adentram ao museu quatro filas, conduzidas, à frente de cada grupo, por uma professora.

A cena descrita inaugura um conjunto de observações de pesquisa realizadas no referido museu espanhol entre os anos de 2010 e 2011. A presente proposta pretende refletir sobre espaço, interação com o público e tecnologias articuladoras das atividades cotidianas de uma instituição dedicada à difusão do conhecimento científico, a partir de um acervo patrimonial constituído em fins do século XIX e acrescido de coleções ao longo do século XX. As observações e as experiências de campo sobre museus de ciências vêm apontando a necessidade de aprofundar temas que se referem ao ambiente social e científico da segunda metade do século XIX, ocasião do surgimento de instituições dedicadas à apresentação de objetos "representativos" de culturas do mundo extraeuropeu. Após 140 anos de inauguração, o Museo Nacional de Antropología de Madrid (MNA) se mantém de portas abertas, recebendo visitantes, turistas, pesquisadores e muitas crianças levadas pelas escolas. Se, por um lado, espaço, arquitetura e patrimônios parecem testemunhar a continuidade objetiva do século XIX aos dias atuais, por outro, o cotidiano do trabalho da recepção desses públicos indica transformações, ajustes e dilemas enfrentados pelo museu, no sentido de dar coerência à sua própria existência e oferecer estratégias de aprendizagem que apoiem as escolas de seu entorno.

Assim, este trabalho se dispõe a concentrar a atenção em um destes universos conceituais marcantes do século XIX, trazendo o museu como centro referencial para pensar, a partir de Michel Foucault, sua interlocução com outros campos, como educação e patrimônio. Diante da atual presença cotidiana de crianças em grupos de visitas ao MNA, algumas questões se destacam com particular estra- 
nhamento em relação às dimensões de disciplina, controle e vigilância observadas. A permanência efêmera dos grupos de escolares no museu permitia o acompanhamento de cerca de uma hora de seu dia dentro da instituição. Portanto, o que se expõe, neste texto, está delimitado pelo trabalho realizado pelo museu para receber seu público, neste caso, um segmento bastante recorrente e específico: estudantes.

Esta proposição de análise, portanto, aborda programas educativos e de visitas guiadas oferecidos pelo MNA aos grupos de crianças e também de adultos, como parte de um rol de instrumentos facilitadores e ordenadores da presença naquele espaço. Considerando a programação mensal de atividades do museu, havia uma séria de ações regulares e temporárias, visando a um "público" específico. Uma importante categoria no contexto estudado é o "público", que, conforme tomado pelo museu, funcionava como uma entidade homogênea, classificável e exigente, a partir da qual se trabalhava para dar conta de suas expectativas.

Dessa forma, o "público" que descrevo nas linhas a seguir era formado por crianças entre 4 e 9 anos de idade, oriundas das escolas de Madrid, que visitavam o museu acompanhadas de suas professoras. É possível afirmar que a escola visitava o museu regularmente, não apenas aquelas crianças observadas, pois, por décadas, elas participam de políticas públicas de incentivo à visitação deste e de outros museus da cidade e escolhiam uma ou duas turmas de alunos para o passeio educativo, como uma estratégia de aprendizado diferenciada do oferecido na sala de aula. A mesma turma não retornaria ao museu nos anos seguintes, cedendo a vez a outros alunos. Portanto, apesar de o MNA receber as mesmas instituições escolares por décadas, em geral, as crianças participam da visita apenas uma vez. E, para receber regularmente um "público" como esse, com demandas bastante distintas de adultos, turistas e famílias (outras constantes classificações do "público"), os funcionários do museu trabalhavam cotidianamente, ordenavam suas atividades, escalavam profissionais, debatiam temas e buscavam soluções para os problemas enfrentados.

É a partir da interação entre todos estes habitantes do museu, entendidos como os que se apropriam daquele espaço, relacionam-se com ele, qualificando-o (INGOLD, 2011), que este trabalho apresenta suas reflexões. A interação dava-se por meio de um enorme esforço de fragmentação do tempo, do espaço e das ações desenvolvidas pelos habitantes, daí o trabalho de Michel Foucault sobre o sistema disciplinar ser, talvez, uma chave para a compreensão dos mecanismos utilizados institucionalmente. A arquitetura e a disposição de salas e coleções são aqui pensadas como espaço, e o agendamento das visitas, a duração do percurso e a escala de profissionais, como tempo. Essas duas categorias de análise são entendidas como parte de um conjunto de ferramentas conceituais e materiais utilizadas como meio 
de proporcionar determinada experiência. Isso significa que o ponto de vista adotado nesta reflexão surge a partir da observação dos usos que estes habitantes do museu fazem destes instrumentos, definindo as dimensões de tempo e espaço como meio de usufruir de determinado tipo de interação.

Utilizam-se como referência os estudos sobre patrimônio, espaço e museus, especialmente a partir da década de 1980, quando as instituições são convocadas a revisar e atualizar seu papel social, diante de críticas e questionamentos vindos principalmente de intelectuais e movimentos sociais. Este trabalho está inserido num contexto mais amplo de pesquisa sobre as interseções entre os museus antropológicos europeus fundados na segunda metade do século XIX e suas condições atuais de existência e autorreflexão.

\section{Universo conceitual}

Este trabalho pretende trazer alguns pontos importantes das análises de Michel Foucault para o debate sobre o mundo dos museus. Compreendendo a dimensão da tarefa, a discussão seguirá de forma mais concentrada nas questões relativas à disciplina e à vigilância, conforme são apresentadas, especialmente, no livro Vigiar e punir (2000).

É a pesquisa de campo que oferece as pistas para o aprofundamento teórico e, nesse sentido, sugere questionar como técnicas e mecanismos do poder disciplinar, conforme apresentado por Foucault em referência aos séculos XVII e XVIII, influem na rotina de trabalho de recepção de visitantes no museu. Conforme descrito anteriormente, grupos de crianças são levados pelas escolas ao museu cotidianamente para visitas oferecidas por funcionários especialmente destacados para tal função. Extremamente ritualizada, a visita dura cerca de uma hora, e os visitantes percorrem a maior parte das cinco salas de exposição permanente do MNA, quando é apresentado um roteiro de objetos e narrativas cuidadosamente escolhido. Textos, fotografias, referências sobre os objetos e sua disposição na montagem das vitrinas compõem a narrativa institucional, dedicada a situar o visitante no suposto contexto de origem daquelas coleções.

É importante informar que o referido museu oferece ao público uma vasta coleção de objetos etnográficos coletados especialmente entre grupos culturais da África, Ásia, América e Oceania nas primeiras décadas do século XX. O museu a organiza por meio de peças consideradas representativas das práticas sociais, como trabalho, festas, religiões, indumentária e adornos, e as explicações oferecidas às crianças e aos adolescentes têm como objetivo levá-los a conhecer o modo de vida de populações dispersas pelo mundo, em contraste com suas próprias experiências. 
Um dado significativo desses grupos de estudantes é a diversidade de nacionalidades entre os alunos. Apesar de a maioria deles serem espanhóis, muitos têm origem latino-americana, árabe ou africana, sendo comum intervenções de reconhecimento dos objetos expostos nas vitrinas como familiares.

Após o acompanhamento de dezenas dessas visitas, surgiram possibilidades de análise sobre pontos centrais do debate oferecido por Foucault: as tecnologias disciplinares aplicadas no interior de instituições como asilos, hospitais e presídios em diálogo com escolas e museus.

Esses temas merecem aprofundamento, pois encontram divergências em seus comentadores e geram perguntas sobre sua pertinência nos dias atuais, entendendo que, apesar de ser observada a manutenção de algumas práticas semelhantes no cotidiano dos museus, elas foram estudadas por Michel Foucault no contexto que parte do século XVII. O interessante em confrontar as observações de campo sobre tais visitas regulares, ritualizadas e rigorosamente disciplinadas com o universo conceitual de Vigiar e punir (2000) seria pensá-las como parte da própria trajetória dos museus e de sua relação com a escola, que permite cumprir uma de suas principais funções sociais, qual seja, a produção e a difusão do conhecimento científico. De acordo com Tony Bennett (2005), o mito de origem dos museus de antropologia está nos chamados gabinetes de curiosidades, que teriam sido espaços internos às casas das elites europeias destinados ao colecionamento de objetos exóticos, originários de expedições fora da Europa, além de exemplares dos reinos animal, vegetal e mineral e mais uma série de elementos materiais que variavam de acordo com o interesse do colecionador. Sendo esse um ambiente essencialmente privado, sua reconfiguração em museu, mais próximo do que hoje conhecemos, deu-se por intermédio da abertura dessas coleções particulares ao público, possibilitando a visitantes e a pesquisadores observar peças então desconhecidas em muitas partes da Europa.

Ainda que consideremos que para tal abertura tenha sido necessária a reclassificação e a reordenação dos objetos, de modo a torná-los compreensíveis aos que os visitariam, a sofisticação da disciplina empregada na fragmentação do tempo e do espaço dos museus de hoje não estava posta naquele período. Conforme detalhado adiante, Foucault nos apresenta um sistema disciplinar interessado nessa fragmentação com objetivo intrinsecamente produtivo, em fábricas e ateliês de séculos anteriores à concepção dos museus modernos. Mais especificamente, observa-se o emprego da ordenação e da disciplina como parte da experiência da visita ao museu.

Em primeiro plano, talvez seja importante trazer brevemente a perspectiva do autor para indicar os caminhos da reflexão que segue. 
Vigiar e punir, publicado originalmente em 1975, oferece um complexo panorama sobre o que Foucault chama de sistema disciplinar, difundido desde a Europa, a partir dos séculos XVII e XVIII. São investigadas técnicas, operações e metodologias que integram um conjunto de relações sociais diferentes do que era observado no período anterior, quando o soberano ocupava um lugar de visibilidade, enquanto seus súditos, obscurecidos, eram subordinados por meio de força, violência e coerção. A virada está na autorregulação permanente e em conquistar corpos aptos a desempenhar funções e tarefas seguindo um repertório compartilhado. Foucault (2006) afirma que o poder disciplinar não seria o único modo de construção do indivíduo moderno, apesar de ser central, porque o tem como alvo e como parceiro, ao mesmo tempo, nesta retroalimentação da disciplina e da vigilância. O poder estaria não em possuir e dominar o corpo do outro, como com o escravo ou o vassalo, determinando o que fazer, mais que isso, internalizar-se-ia a função e executá-la-ia de forma mais rápida e eficaz, a partir da disciplina. Por intermédio desse modus operandi, o autor apresenta um modo de poder espraiado, sem um centro de produção único responsável por impor regras, disciplinar e punir.

O poder disciplinar, conforme apresentado por Foucault, atende mais pela atenção ao processo do que por seu resultado, pois é no desempenhar da ação que se determina a maior eficiência que o corpo pode oferecer na sua relação com o espaço e com o tempo. Instaura-se, assim, a relação utilidade-docilidade dos corpos:

O momento histórico das disciplinas é o momento em que nasce uma arte do corpo humano, que visa não unicamente ao aumento de suas habilidades, nem tampouco a aprofundar sua sujeição, mas à formação de uma relação que no mesmo mecanismo o torna tanto mais obediente quanto é mais útil, e inversamente (FOUCAULT, 2000, p. 164).

\section{A disciplina}

Para aprofundar o tema, Foucault faz uma opção metodológica interessante, que se trata de deslocalizar o poder. Isso induz a buscar, nas técnicas, instrumentos e tecnologias, ou seja, nas periferias do sistema, a dinâmica do poder exercido, sem contudo atribuir um centro exclusivo, interessando-se por um "dispositivo de saber" em vez de ideologias mais amplas de poder (POGREBINSCHI, 2004). Isso significa desfocar a imagem do poder emanado por um centro soberano e enxergá-lo operando na maquinaria cotidiana. O descolamento desta noção de um sujeito detentor e executor possibilita enxergar uma rede na qual o poder circula: “[...] o poder não pertence nem a alguém, nem, aliás, a um grupo; só há poder porque há dispersão, intermediações, redes, apoios recíprocos, diferenças de potencial, defasagens, etc." (FOUCAULT, 2006, p. 7). Tomar o ponto de vista da técnica para a análise, e não 
da instituição global, leva a pensar na afetividade do poder específico, ou seja, nos efeitos diretos que gera.

É importante ressaltar que Foucault fala de um poder disciplinar que produz marcando um profundo sentido positivo e não repressivo, por isso sua análise percorre fábricas e ateliês que, a partir da ordenação de pessoas, técnicas e instrumentos no tempo e no espaço, aumentam sua capacidade de produção. Sua análise ultrapassa, no entanto, a dimensão econômica presente nessa produção, quando argumenta que se produz conhecimento a partir deste novo modelo difusor do poder. Entende-se aí a construção de saber de distintas ordens, desde a aprendizagem do oficio até, no limite, a ideia de indivíduo, gerando produção econômica e produção de conhecimento simultaneamente. Neste ponto, a missão difusora do saber dos museus encontra os benefícios da disciplina.

No contexto das visitas oferecidas às crianças pelo MNA, essa dimensão da produtividade parece marcante pela formatação de um modelo de interação das pessoas com o museu, baseado na agenda (tempo) e no percurso (espaço) da visitação. A disciplina dos corpos marca a experiência ritual de entrada, permanência e saída do museu, sendo altamente regrada. Um conjunto de normas era apresentado ao grupo no momento de sua recepção, antecipando o que aconteceria dentro do espaço do museu. É interessante notar que, nessa recepção e na apresentação das condutas esperadas, objetivava-se reduzir a incidência de desvios, ou seja, de acontecimentos que perturbassem a dinâmica proposta. Assim, as regras tendiam a organizar não exclusivamente as pessoas, mas o tempo e o espaço por meio de seus comportamentos.

As crianças chegavam ao museu após a ordenação de diferentes tarefas e etapas por parte da escola, desde a escolha das turmas a saírem em visitação e dos museus a serem visitados, até o desembarque dos alunos na porta do museu. A partir deste instante, as professoras, que até então eram as responsáveis por ordenar e guiar o grupo, cedem sua posição de liderança a um ou dois funcionários do museu, incumbidos de oferecer um determinado percurso espacial e de conteúdo, dentro de um tempo limitado e controlado. Para tanto, por parte do museu, também havia tarefas a serem fragmentadas, distribuídas e cumpridas por seus profissionais. Escolhia-se quem receberia cada grupo, de acordo com uma escala de trabalho, que, por sua vez, estava atrelada a uma agenda de atividades desses e de outros profissionais e também aos espaços físicos do museu, sempre com o cuidado para que apenas um grupo ocupasse cada uma das cinco salas.

Nessas visitas com crianças, buscava-se que as regras e os instrumentos de controle do museu ficassem bastante claros, para tanto, eram constantemente apresentadas e relembradas na orientação da visita. Parecia haver menos cons- 
trangimento e mais eficácia ao abordar uma criança ou um grupo delas com delimitações e normas de comportamento do que ao fazê-lo com adultos, embora o museu o fizesse. Em relação aos adultos, a abordagem raramente se dava por meio dos guias que apresentavam as visitas. Estes costumavam deixar os integrantes do grupo muito mais à vontade para se dispersar pela sala, mesmo enquanto a explicação de uma peça específica acontecia.

No entanto, eram os "vigilantes de sala" os maiores responsáveis do museu por apresentar regras aos visitantes adultos, quando estes cruzavam algum espaço proibido, como uma sala em montagem de nova exposição, quando falavam muito alto ou quando se aproximavam de algum objeto. A curiosa denominação "vigilantes de sala" aplicava-se aos funcionários que permaneciam sentados ou caminhando dentro de cada galeria, responsáveis por tudo que ocorresse em cada uma. Para situações idênticas às que ocorriam com crianças, recorria-se à intervenção dos vigilantes somente nos momentos em que não havia alternativa, ou quando precisavam atuar rapidamente, como no caso de uma criança que tentava abrir uma das vitrinas de objetos. De um modo geral, as repreensões feitas pelos "vigilantes de sala" a respeito do "mau comportamento" de alguma criança eram direcionadas aos professores ou aos guias das visitas, também funcionários do museu, como se o museu devesse ensinar a regra à criança, mas aos adultos devesse cobrar seu cumprimento.

Diferentemente dos grupos organizados de adultos, as crianças percorriam praticamente todo o museu durante a visita, e as peças escolhidas para serem apresentadas eram sempre as mesmas. Durante anos, o MNA ofereceu exatamente o mesmo roteiro de visita aos grupos de crianças. Esse percurso foi elaborado pelos conservadores de modo que pudesse ser apresentado por qualquer pessoa. Dessa forma, ainda que tenham mudado os funcionários responsáveis pelas visitas ao longo dos anos, garantia-se que nada fosse alterado no programa, confiando que assim seria controlada com maior efetividade a transmissão daquele conhecimento. Os grupos então caminhavam sempre guiados pelo "monitor" pelas salas, detendo-se em algumas peças que eram explicadas com abordagens pouco diferentes para as crianças menores ou maiores. A maior frequência de idade do público infantil no museu era de até 8 anos.

Um dado interessante a ser observado é a postura dos grupos dentro do museu. O responsável por conduzir a visita caminhava à frente do grupo, seguido pelas crianças, separadas em duas filas, e, por fim, pelas professoras. Esse alinhamento das crianças ocorria no momento do deslocamento entre salas, cuidando para que nenhuma delas se desligasse do grupo ou demorasse na observação dos objetos. Ao chegar nas salas, as filas se desfaziam, e, em algumas ocasiões, as crianças 
eram convidadas a se sentar no chão em frente ao objeto ou à vitrina escolhida pelo monitor, que permanecia de pé, assim como as professoras. Era curioso como a posição dos corpos de todos esses personagens parecia identificar sua posição na fila, conforme comentado por Foucault:

$\mathrm{Na}$ disciplina, os elementos são intercambiáveis, pois cada um se define pelo lugar que ocupa na série e pela distância que o separa dos outros. A unidade não é portanto nem o território (unidade de dominação), nem o local (unidade de residência), mas a posição na fila: o lugar que alguém ocupa numa classificação, o ponto em que se cruzam uma linha e uma coluna, o intervalo numa série de intervalos que se pode percorrer sucessivamente. A disciplina, arte de dispor em fila e técnica para a transformação dos arranjos. Ela individualiza os corpos por uma localização que não os implanta, mas os distribui e os faz circular numa rede de relações (FOUCAULT, 2000, p. 172, grifo do autor).

Uma vez dentro da galeria, as professoras imediatamente procuravam por um sofá e ali se sentavam ou permaneciam de pé ao fundo do grupo de crianças, também sentadas no chão. Já o guia, em algumas vitrinas específicas, ajoelhava-se na frente do grupo, estabelecendo um patamar de altura ainda diferenciado das crianças, mas mais próximo a elas. Na primeira vez em que estive presente em uma dessas visitas, sentei-me no chão junto com as crianças, mas logo percebi que chamava a atenção de todos. Esperava-se, talvez, que eu me posicionasse de acordo com o que pressupunha o meu lugar na fila: como adulta, poderia ocupar a posição do guia, das professoras, dos demais visitantes ou funcionários do museu, mas, aparentemente, não o lugar das crianças.

Em outra ocasião, três guias diferentes conduziam grupos, cada um ocupando um andar do museu. Parecia um enorme trabalho de coordenação, porque eles deveriam cumprir um tempo pré-fixado para a explicação dos conjuntos de peças e seguir adiante para outra sala, pois o segundo grupo já estava pronto para entrar. A arquitetura vazada entre as salas fazia com que, até no andar de baixo, pudesse ser ouvida perfeitamente as conversas dos grupos. Nas ocasiões observadas, os guias reuniam todas as crianças no hall principal, no início da visita, para explicar as regras, começando por dizer que aquele espaço era um museu e que portanto deveria ser feito silêncio.

O espaço parecia estar determinado por uma organização funcional, assim como o tempo, de modo que se desse conta de comportar os visitantes distribuídos por suas dependências. Tratava-se de uma proposta de fruição do museu balizada por enquadramentos muito precisos, no que se referia ao tempo e ao espaço. A disponibilidade para ser recebido pelos guias implicava agendar previamente data e horário, além de formar e organizar os grupos escolares para a saída da escola em direção ao museu e seu seguro retorno. Apresentava-se como uma enorme sequência de atividades ordenadas, de forma a construir a experiência de estar em um museu. 
Com relação ao espaço, os objetos estavam dispostos em cada sala, classificados em origem, data, materiais utilizados na confecção, contexto local, etc., e também com um desejo de disposição no espaço. Havia uma dinâmica organizadora que definia a posição de determinada peça ao lado de uma coleção, e não de outra, além de um desenho espacial (uma arquitetura) das salas pensada de modo a atender, entre outras coisas, à exigência de pessoas em circulação.

É curioso como as galerias eram apresentadas de maneira ordenada. As coleções eram classificadas e separadas por salas; dentro de cada sala, por temáticas específicas; dentro de cada temática, por um conjunto de vitrinas; dentro de cada vitrine, por objetos dispostos ao lado de outros, que, juntos, conformavam leituras possíveis. Tudo isso apresentado num ambiente limpo, pensado, planejado e organizado, em que se controlava o tempo, o espaço e os acontecimentos, por meio dos vigilantes de sala e de técnicas compartilhadas de autorregulação. Porém, nem sempre foi assim. A visibilidade dos corpos, descrita por Foucault n'O Panoptismo, instaura um mecanismo de indução da consciência de estar sendo permanentemente observado, o que garante a automatização do exercício de poder (FOUCAULT, 2000). Coisas e pessoas recebiam seus devidos lugares no espaço e no tempo do museu e deveriam seguir o repertório acordado no início de cada visita, sem desvios, sem improvisos e sem perturbação da ordem. O mínimo movimento em sentido contrário era rapidamente repreendido e controlado, voltando à normalidade regular.

O que parecia algo simples, o instante da descoberta do novo por parte das crianças por meio de sua presença no museu, era, na verdade, resultado de uma intrincada organização disciplinar, que não se esgotava ao adentrar o espaço institucional. Ao contrário, a partir dali, havia um novo conjunto de regras de mediação da experiência. E parecia ser justo o confronto de autoridades e entendimentos sobre o cumprimento de cada etapa desse processo que gerava conflitos e constrangimentos, especialmente entre os funcionários do museu e os funcionários das escolas, como no caso dos atrasos da chegada dos grupos ao museu ou no descontentamento de professores com o modo de expor os conteúdos apresentados na visita. A vigilância surgia, então, como uma espécie de dispositivo de prevenção e correção, buscando regular as ações dos habitantes do museu, de modo a não ocasionar desvios possivelmente geradores de conflitos.

\section{Museu como instituição de poder?}

Sobre o ambiente expositivo, Tony Bennett (1996) comenta que todo o aparato que envolve a arquitetura e a projeção de espaços internos dos museus do século XIX se deslocou do formato que atendia aos interesses privados de aristocratas e 
príncipes para um contexto de instrução pública. Foucault chama a atenção para a sensível modificação estrutural quando a arquitetura deixa de ser composta para ser vista, como os palácios ou como os locais de observação do exterior, as fortalezas. Passa, então, a funcionar como ordenadora do espaço interno, de modo a tornar visíveis os que se encontram nele: "[...] agir sobre aquele que abriga, dar domínio sobre seu comportamento, reconduzir até eles os efeitos do poder, oferecê-los a um conhecimento, modificá-los" (FOUCAULT, 2000, p. 197).

Embora muitos edifícios de museus construídos no século XIX e início do século XX mantenham sua fachada com inspirações nos templos gregos e na Antiguidade Clássica, há resquícios de momentos anteriores da concepção de instituições no contexto que parte do Renascimento, como o British Museum (Londres), Altes Museum (Berlin), Petit Palais (Paris) e Musée Royal de l'Afrique Centrale (Bélgica). A disposição interna das salas aponta características de organização do espaço conformadas à tarefa de expor objetos e receber pessoas para observá-los.

Desse modo, as regras ensinadas no ambiente do MNA serviam para aprender como se comportar ali, mas, especialmente, como se comportar em outros lugares, no limite, em sociedade. Funcionava mesmo como um complemento da escola, em que as crianças eram convidadas a se manifestar em momentos específicos, caminhar de forma previamente determinada, seguir as instruções do guia, fazer silêncio, olhar para o objeto em explicação, compreender que deveriam ouvir antes de falar, etc., e a negativa estava presente todo o tempo. Nas palavras de Barbara Kirshenblatt-Gimblett, "[...] not only do ordinary things become special when placed in museums settings, but also the museum experience itself becomes a model for experiencing life outside its walls" (1991, p. 410).

Ao longo do percurso da visita, as crianças entravam em contato com novidades, curiosidades e surpresas, ao conhecer objetos e histórias novos, mas cada uma dessas novidades era experimentada a partir de regras previamente estabelecidas, relembradas a todo instante. Assim, a descoberta do novo e o processo da domesticação dos corpos (FOUCAULT, 2000) coexistiam e cooperavam, relegando ao museu o rótulo de instância educativa e civilizadora, como se servisse a uma disposição específica.

No entanto, configurações como esta demandam um olhar atento, uma descrição densa (GEERTZ., 1989) sobre como esse ambiente se desenvolve, porque os usos e as apreensões possíveis são subvertidos pelos habitantes do museu a todo tempo. Por isso a importância de não tomar as análises tipologicamente, pois diferentes modos de interação estão presentes, o que faz com que o museu não seja nunca apenas espaço destinado à concretização de um objetivo único. 
Foucault e Bennett são trazidos neste trabalho justamente para apresentar uma dessas possíveis leituras, que dialoga com o debate de requalificação do papel social dos museus hoje. Tratam de elementos que oferecem boas perspectivas para pensar o espaço do museu, os percursos de visitação, a disposição de pessoas em cada um desses espaços e a aprendizagem das crianças sobre como se comportar bem, isto é, de acordo com a regra. O poder disciplinar, conforme apresentado por Foucault, acontece por meio de diferentes procedimentos, técnicas, tecnologias, dispositivos e ferramentas, e o resultado obtido varia enormemente, produzindo classificações e posicionamentos dentro da escala, medição de quantidades, análise de comportamentos, redução de singularidades, tornando visível para conhecer. $\mathrm{O}$ ponto central da disciplina seria conseguir tirar o maior número possível de efeitos positivos e produtivos por meio dessas operações.

Desde a publicação de Vigiar e punir, este trabalho de Michel Foucault vem sendo experimentado a partir de outros contextos e disciplinas, sendo o museu um deles. Tomado como instituição de encarceramento, Douglas Crimp (1993) afirma que a história da arte seria uma das disciplinas que mereceria o estudo a partir de Foucault, pois estaria para o museu assim como as concepções de criminalidade e loucura estão para o presídio e o manicômio. $\mathrm{O}$ aprisionamento à obra de arte se daria em função da estrutura e da narrativa que o museu elabora ao expor, criando a ficção de uma representação coerente do mundo a partir de ordenações, classificações e justaposições espaciais de pequenos fragmentos. Esse conjunto dado pelo museu marcaria seu suposto entendimento sobre o mundo (CRIMP, 1993).

Tony Bennett foi criticado por Randolph Starn (2005) por atribuir ao museu o caráter libertador, quando trata da abertura das coleções privadas e gabinetes de curiosidades ao público, por meio dos museus de história natural, arqueologia e antropologia. O translado dessas coleções para o museu traria consigo uma ideia de bem público, garantindo a difusão de conhecimento para além dos ambientes privados nos quais os objetos estavam resguardados. Ao contrário do que Starn comenta, Bennett parece plenamente consciente da capacidade ordenadora do museu, e não a descarta. Em Civic Laboratories, Bennett argumenta não haver nada novo em atribuir ao museu a intencionalidade de moldar capacidades cívicas e ordenar uma leitura de mundo, pois já conhecemos seu papel civilizatório desde o século XIX (BENNETT, 2005).

Isso nos remete diretamente à Foucault, no que se refere ao encarceramento e à liberdade, quando pensados por intermédio de espaços e instituições. Para o autor, o trabalho dos arquitetos na construção de um edifício pode ser um exercício de promoção da liberdade, no entanto, sua persistência não estaria totalmente garantida, mas apenas no momento da proposição e construção (e ainda destruição) 
do edifício. Para Foucault (2000), a única garantia da liberdade, numa oposição à opressão, seria a própria liberdade. E é nesse sentido que o autor afirma que a prática da liberdade pelas pessoas que habitam o espaço é que pode fazer valer a intencionalidade do arquiteto. Na sequência, relaciona o panóptico a Rousseau e à Revolução Francesa, tratando de um conceito muitas vezes pensado como opressor, por sua aplicação prioritária nos presídios, mas é justamente a capacidade de dar visibilidade que tornou possível sua incorporação pelo ambiente revolucionário francês de expurgar qualquer margem de espaço escuro. Nas palavras de Foucault: "[...] demolir estas câmaras escuras onde se fomentam o arbitrário político, os caprichos da monarquia, as superstições religiosas, os complôs dos tiranos e dos padres, as ilusões da ignorância, a epidemia" (2000, p. 216). Este talvez seja um dos melhores indicadores para pensar que o museu, assim como as demais instituições, pode ser experimentado de diferentes formas, como espaço de visibilidade, liberdade, vigilância ou opressão.

O Museo Nacional de Antropología de Madrid integra este conjunto de instituições que dá visibilidade pública a uma coleção particular. Tratava-se, no entanto, de um acervo de objetos, corpos e instrumentos para o estudo da medicina do século XIX, que se misturava às peças coletadas pelas expedições às colônias e às ex-colônias espanholas e europeias. A residência do médico fundador do museu, espaço de sociabilidade e debates entre seu grupo de pesquisadores, transformou-se em local de exposição dessas coleções. Pilar Romero de Tejada (1992) descreve os esforços de Dr. Velasco (criador do MNA) em angariar fundos para a reforma da casa e inauguração do museu na década de 1870, na Espanha. Os argumentos para a construção do edifício aparecem inseridos no contexto científico da época, ao que parece, sendo desejo de seu criador construir "um templo à ciência antropológica" (1992, p. 13), cercado pelo Jardim Botânico, pelo Museo del Prado e pelo Observatório Astronômico, localizados no entorno. Conforme mencionado, sua fachada é inspirada nos templos gregos e traz gravada a inscrição em latim: "Nosce te ipsum", "conhece-te a ti mesmo".

Para pensar a arquitetura da visibilidade e vigilância neste museu, proponho uma breve descrição de sua disposição espacial interna nos anos 2010 e 2011: composta por sete salas de visitação. A primeira delas abriga o grande hall de entrada, por onde todos os visitantes devem passar para dirigirem-se aos demais espaços. Esse hall conforma-se como uma grande sala sem cobertura (sem teto), na qual as peças estão todas expostas em vitrinas e backlights nas paredes laterais. Posicionado no centro desta sala, o visitante pode ver, acima, as varandas internas dos demais andares do prédio, e quem se encontra nos andares superiores, igualmente, pode ver aqueles que cruzam o hall para acessar as demais salas (Figura 1). 
Figura 1 - Vista interna do MNA: hall principal; ao fundo, entrada da Sala de Religiones Orientales; canoas filipinas suspensas; Sala de África no segundo andar; vigilante de sala no canto direito; Sala de América no terceiro andar

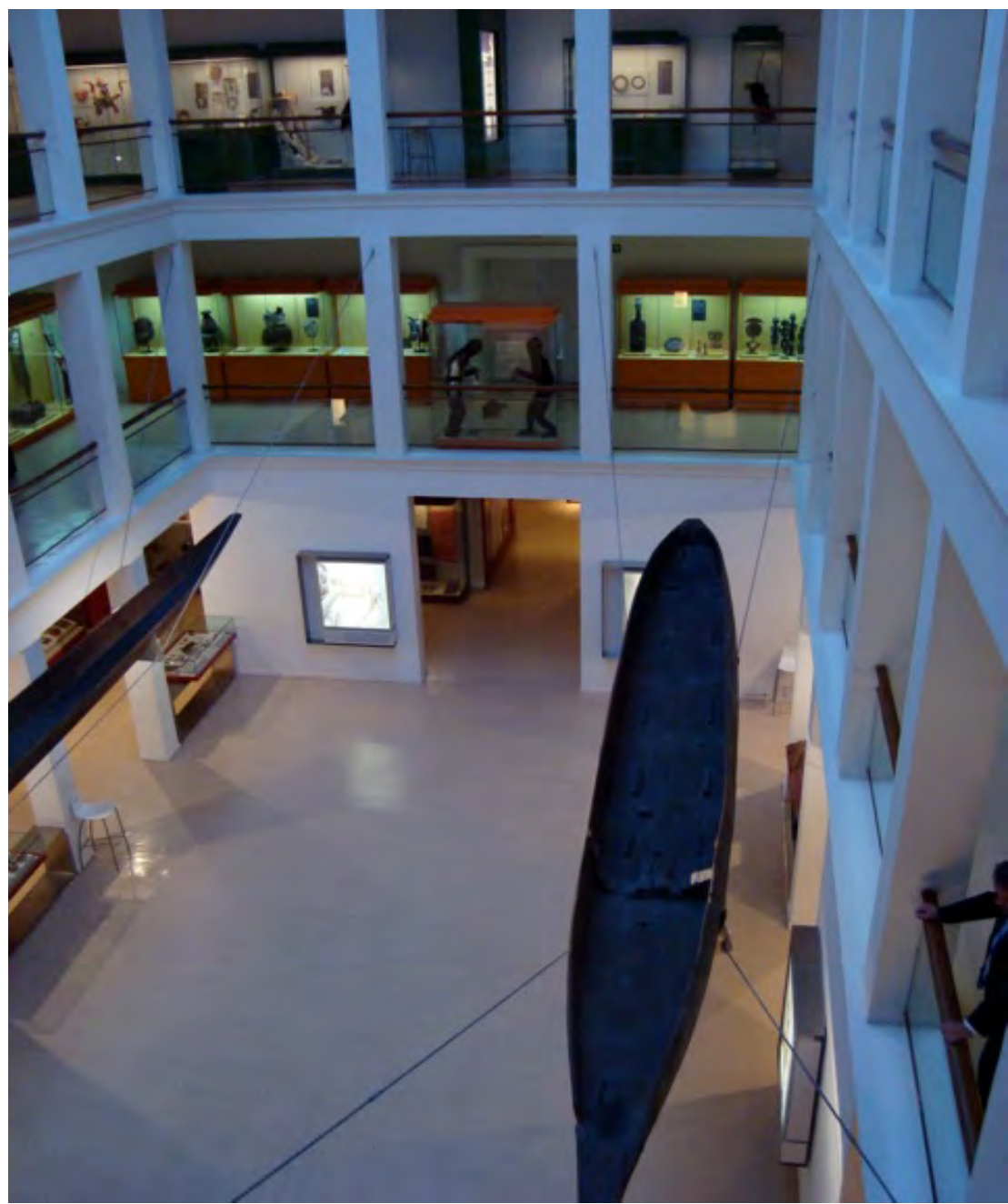

Fonte: acervo pessoal da autora.

A exposição apresentada no hall trata de uma instrução geral sobre os continentes presentes no museu e, principalmente, da coleção de objetos etnográficos das Ilhas Filipinas. Esta coleção está composta de dois dos objetos mais impressionantes do museu: duas grandes canoas de madeira, suspensas por cabos de aço e fixadas entre o primeiro e o segundo andar. Do lado esquerdo do hall, está a Sala de los Orígenes del Museo ou Sala de Antropología Física, com uma coleção de crânios, esqueletos, múmias e máscaras mortuárias; à frente, a Sala de Religiones Orienta- 
les, com suntuosas peças referentes ao Budismo, ao Islã e ao Hinduísmo. Do lado direito do hall, ainda no primeiro andar, estão duas salas sequenciais destinadas a exposições temporárias.

As duas últimas salas de exposição do museu localizam-se no segundo e no terceiro andar e têm formato de corredor circular, já que são como varandas, das quais se vê o hall logo abaixo. O segundo andar abriga a exposição denominada "África", com objetos recolhidos em diferentes países do continente, e apresenta uma importante vitrina de máscaras. Já o terceiro andar guarda a Sala de América e sua bela coleção de plumárias amazônicas.

Michel Foucault dedica boa parte de sua obra a pensar as disposições espaciais das instituições que estuda, pensadas como elementos estratégicos dessa ordenação para produção. Nos museus, não seria diferente, e o MNA talvez ajude a refletir sobre esses mecanismos aplicados à dinâmica cotidiana entre museus e visitantes. Sua arquitetura interna destaca o hall central como um espaço que é visto por todos os demais, além de as varandas dos dois andares permitirem observar a movimentação nas áreas de maior circulação do museu. Se para acessar qualquer espaço de exposição do primeiro andar é preciso passar pelo hall, e este é visto pelos outros dois andares, qualquer situação que aconteça nesses espaços ou qualquer ruído que ocorra ali, imediatamente, suscita a curiosidade de quem habita as varandas ou o térreo, que pode rapidamente conferir o que se passa.

Assim, tudo se passava como se houvesse um padrão de comportamento determinado e conhecido por todos, cada um desempenhando sua função de acordo com a regra. Os desvios deveriam ser corrigidos rapidamente pelos responsáveis pela vigilância num determinado espaço, ou seja, em cada uma das salas de exposições. Mas, ainda que houvesse um indivíduo vigilante para cada fragmento de espaço, os demais visitantes ou funcionários do museu vigiavam o vigilante de sala no cumprimento de sua tarefa. Assim como no panóptico, todos se sentiam como se vários olhos os observassem.

Mecanismos como esses integram o conjunto de comportamentos que o museu convida os visitantes a compartilhar. Como num microcosmo da vida social, a experiência é mediada por recursos que tornam mais produtivo o tempo dedicado à visita:

Sensory atrophy is coupled with close focus and sustained attention. All distractions must be eliminated - no talking, rustling of paper, eating, flashing of cameras. Absolute silence governs the etiquette of symphony halls and museums. Aural and ocular epiphanes in this mode require pristine environments in which the object of contemplation is set off for riveting attention. Rules posted at the entrance and guards within ensure that decorum prevails (KIRSHENBLATT-GIMBLETT, 1991, p. 416). 
Com a descrição dos espaços de exposição do museu, pretende-se sublinhar, primeiro, a existência de pessoas inteiramente dedicadas à tarefa de observar, controlar e corrigir comportamentos. Não apenas visitantes ocasionais eram interpelados, mas também trabalhadores com distintas responsabilidades dentro da instituição, pois as regras não fazem distinções.

\section{Considerações finais}

Este trabalho pretendeu adentrar o universo de Michel Foucault no que diz respeito às concepções sobre o poder disciplinar, a partir do cotidiano de trabalho e interação entre funcionários de um museu e crianças em grupos escolares, seu principal público. $\mathrm{O}$ cruzamento das referências de instituições citadas pelo autor sugeriu sua aplicação ao material de campo do Museo Nacional de Antropología de Madrid, inicialmente, em função das observações a respeito do espaço e da arquitetura do museu. Entretanto, na sequência, os conceitos de ordem, visibilidade e vigilância pareceram pertinentes às observações sobre o funcionamento das visitas regularmente oferecidas.

Conforme comentado anteriormente, o cotidiano das atividades educativas que o museu disponibiliza às crianças e às escolas sofre inúmeros desencaixes, seja pela quebra ocasional de regras e acordos prévios, seja pelo desejo consciente ou não de subverter a ordem e experimentar o museu como um ambiente desconhecido. Essas rupturas constroem novas dinâmicas, que são, em muitos casos, inclusive, absorvidas como atualizações da regra, e fazem daquele espaço um lugar mais adequado às práticas cotidianas de seus habitantes. A liberdade, como mostra Foucault, possibilita vivenciar as aprendizagens de várias maneiras, e a trajetória do Museo Nacional de Antropología de Madrid nos revela este esforço de reorientar-se diante das demandas que recebe.

Experiências de programas educativos em museus levantam questionamentos sobre o papel dessas instituições na formação de crianças e adolescentes. Para além dos conteúdos e conhecimentos específicos que cada museu aporta, em concordância com o que se espera para o período escolar dos grupos de estudantes que os visitam, há o propósito de ensinar valores, regras, condutas e comportamentos. Estudar aspectos do sistema disciplinar do século XVII e XVIII talvez possa levar a perguntas atuais sobre o papel social das instituições museológicas e suas formas de abordagem junto à escola nos dias de hoje. 


\section{Referências}

BENNETT, T. The exhibitionary complex. In: GREENBERG, R.; FERGUSON, B.; NAIRNE, S. Thinking about exhibitions. London; Nova Iorque: Routledge, 1996. p. 58-80.

Civic laboratories: museums, cultural objecthood and the governance of the social. Cultural Studies, London, UK, v. 19, n. 5, p. 521-547, 2005.

CRIMP, D. On the museum's ruins. Cambridge; Massachusetts: The MIT Press, 1993.

FOUCAULT, M. O poder psiquiátrico: curso dado no Collège de France (1973-1974). São Paulo: Martins Fontes, 2006.

. Vigiar e punir. Rio de Janeiro: Vozes, 2000.

GEERTZ, C. Uma descrição densa: por uma teoria interpretativa da cultura. In: GEERTZ, Clifford. A interpretação das culturas. Rio de Janeiro: LTC, 1989. p. 3-21.

INGOLD, T. Against the notion of space: place, movement, knowledge. In: Ingold. Tim. Being Alive: essays on movement, knowledge and description. Londres; Nova Iorque: Routledge, 2011. p. $145-155$.

KIRSHENBLATT-GIMBLETT, B. Objects of Ethnography. In: KARP, I.; LAVINE, S. Exhibiting Cultures - the poetics and politics of museum display. Washington, D.C.: Smithsonian Institutuion Press, 1991. p. 386-443.

POGREBINSCHI, T. Foucault, para além do poder disciplinar e do biopoder. Lua Nova, São Paulo, n. 63, p. 179-201, 2004.

ROMERO DE TEJADA, P. Um templo a la ciência - Historia Del Museo Nacional de Etnologia. Madrid: Ministério de Cultura - Dirección General de Bellas Artes y Archivos, 1992.

STARN, R. A historian's brief guide to new museum studies. The American Historical Review, Oxford University Press, Oxford, v. 110, n. 1, p. 68-98, 2005. 